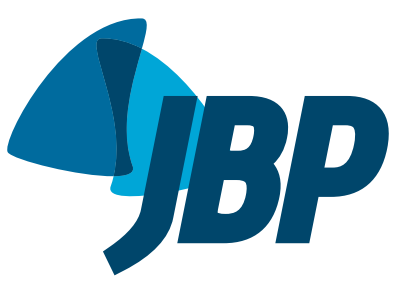

1. Programa de Pós-Graduação em Bases Gerais da Cirurgia, Faculdade de Medicina de Botucatu, Universidade Estadual Paulista - UNESP Botucatu (SP) Brasil.

2. Serviço de Cirurgia Torácica, Departamento de Cirurgia e Ortopedia, Faculdade de Medicina de Botucatu, Universidade Estadual Paulista UNESP - Botucatu (SP) Brasil.

3. Programa de Pós-Graduação em Medicina, Faculdade de Medicina de Botucatu, Universidade Estadual Paulista - UNESP - Botucatu (SP) Brasil.

a. (D) http://orcid.org/0000-0002-5509-0862

b. (iD http://orcid.org/0000-0002-3400-2309

c. (D) http://orcid.org/0000-0002-6246-384X

d. (D) http://orcid.org/0000-0003-2330-9337

Submitted: 17 May 2017

Accepted: 15 December 2017

Study carried out at the Faculdade de

Medicina de Botucatu, Universidade

Estadual Paulista, UNESP, Botucatu (SP)

Brasil.

\section{Hyperhidrosis: prevalence and impact on quality of life}

\author{
Erica Nishida Hasimoto',a, Daniele Cristina Cataneo ${ }^{2 . b}$, \\ Tarcísio Albertin dos Reis ${ }^{3, c}$, Antonio José Maria Cataneo ${ }^{2, \mathrm{~d}}$
}

\begin{abstract}
Objective: To determine the prevalence of primary hyperhidrosis in the city of Botucatu, Brazil, and to evaluate how this disorder affects the quality of life in those suffering from it. Methods: A population survey was conducted in order to identify cases of hyperhidrosis among residents in the urban area of the city, selected by systematic cluster sampling. In accordance with the census maps of the city, the sample size should be at least 4,033 participants. Ten interviewers applied a questionnaire that evaluated the presence of excessive sweating and invited the subjects who reported hyperhidrosis to be evaluated by a physician in order to confirm the diagnosis. Results: A total of 4,133 residents, in 1,351 households, were surveyed. Excessive sweating was reported by 85 residents (prevalence $=2.07 \%$ ), of whom $51(60 \%)$ were female. Of those 85 respondents, 51 $(60 \%)$ agreed to undergo medical evaluation to confirm the diagnosis and only $23(45 \%)$ were diagnosed with primary hyperhidrosis (prevalence $=0.93 \%$ ). Of the 23 subjects diagnosed with primary hyperhidrosis, $11(48 \%)$ reported poor or very poor quality of life. Conclusions: Although the prevalence of self-reported excessive sweating was greater than $2 \%$, the actual prevalence of primary hyperhidrosis in our sample was $0.93 \%$ and nearly $50 \%$ of the respondents with primary hyperhidrosis reported impaired quality of life.

Keywords: Hyperhidrosis/epidemiology; Hyperhidrosis/diagnosis; Quality of life.
\end{abstract}

\section{INTRODUCTION}

Hyperhidrosis is a disorder characterized by excessive sweating beyond the level physiologically required for thermoregulation. ${ }^{(1,2)}$ Its etiology can be primary (idiopathic)-recent studies having tried to demonstrate a putative genetic link ${ }^{(3,4)}$-or secondary to other diseases, such as infections, neurological disorders, metabolic disorders, neoplasms, spinal cord injuries, anxiety, and stress. ${ }^{(5,6)}$ For those suffering from it, hyperhidrosis causes profound embarrassment-at the social, psychological, professional, and emotional level. The degree of impairment of quality of life (QoL) in patients with hyperhidrosis is comparable to that seen in patients with chronic diseases, such as severe psoriasis, kidney failure, and advanced-stage rheumatoid arthritis. ${ }^{(7)}$ It is still undetermined whether or not the incidence of hyperhidrosis is actually higher in females; the fact that women more often seek treatment for hyperhidrosis in clinical practice gives a false impression that it is predominant in females. ${ }^{(8,9)}$ The areas commonly affected by primary hyperhidrosis $(\mathrm{PH})$ are the scalp, face, hands, armpits, and feet. Making the distinction between $\mathrm{PH}$ and secondary hyperhidrosis ( $\mathrm{SH}$ ) is crucial to defining the most appropriate treatment. Video-assisted thoracoscopic sympathectomy is the standard treatment for $\mathrm{PH}$ of the hands and armpits, ${ }^{(10,11)}$ with a clearly high level of satisfaction and a low rate of complications, especially for low nerve blocks. ${ }^{(12,13)}$

There are few data on the worldwide prevalence of hyperhidrosis, reported values ranging from $0.072 \%$ to $9 \% .{ }^{(7,14-24)}$ The studies performed to date have used diverse methods, evaluating populations in restricted age groups and with distinct characteristics.

The aim of this study was to establish the prevalence of PH and to determine how it affects the QoL of patients with the condition.

\section{METHODS}

\section{Ethics}

This study was initiated after approval by the Research Ethics Committee of the College of Medicine of Botucatu - State University of São Paulo (Reference no. 2831/08).

\section{Study population}

The study involved the residents of households in the urban area of the city of Botucatu, Brazil. We selected

Correspondence to:

Erica Nishida Hasimoto. Serviço de Cirurgia Torácica, Departamento de Cirurgia e Ortopedia, Faculdade de Medicina de Botucatu, Universidade Estadual Paulista, UNESP, Avenida Prof. Mário Rubens Guimarães Montenegro, s/n, CEP 18618-687, Botucatu, SP, Brasil.

Tel.: 5514 3880-1546 or 5514 3880-1528. E-mail: ericanh80@hotmail.com or ehasimoto@fmb.unesp.br

Financial support: This study received financial support from the São Paulo Research Foundation (Fundação de Amparo à Pesquisa do Estado de São Paulo,

FAPESP) 
households by systematic cluster sampling, using census maps created by the Brazilian Institute of Geography and Statistics for population counts and household registration. ${ }^{(25)}$

\section{Sample size calculation}

The sample size for the city of Botucatu was calculated considering the prevalence of hyperhidrosis in the United States (2.8\%). ${ }^{(15)}$ Considering that the population over 5 years of age in Botucatu consisted of 113,055 residents, and using an accuracy of $0.5 \%$, we calculated a sample size of 4,033 residents. ${ }^{(25)}$

According to data from the Brazilian Institute of Geography and Statistics, each household in Botucatu has approximately three residents; therefore, at least 1,344 households should be surveyed.

\section{Pilot study}

The pilot study involved a total of 30 households in two districts (Vitoriana and Rubião Junior). Field work personnel applied a questionnaire developed by the researchers in order to test it and to determine the best way to approach subjects.

After the end of the pilot study, the interviewers who had been selected for field work underwent theoretical and practical training.

\section{Inclusion criteria}

The study included all subjects that agreed to participate and gave written informed consent. The selected resident interviewee was questioned about whether other residents in the household over 5 years of age showed excessive sweating. If so, those residents were also included in the study.

\section{Interview}

Ten previously trained interviewers applied a questionnaire that evaluated age, sex, excessive sweating (of the scalp, face, palms, armpits, soles of the feet, other regions, or two or more regions), age at symptom onset, psychosocial effect, predisposing factors, and similar cases within the family. A questionnaire specific for hyperhidrosis was applied to the subjects who reported excessive sweating. ${ }^{(26)}$ The questionnaire consisted of 20 questions evaluating five domains: functional, social, personal, emotional, and special conditions. On each question, subjects were allowed to give only one response (scored from one to five), categorizing QoL as excellent (1), very good (2), good (3), poor (4), or very poor (5) for each situation. Therefore, the overall score could range from 20 (the best possible score, with a score of 1 on each of the 20 questions) to 100 (the worst possible score, with a score of 5 on each of the 20 questions). ${ }^{(26)}$

\section{Medical evaluation}

Subjects identified as having hyperhidrosis were selected to receive a home visit by a thoracic surgeon. For those who preferred, a physician consultation was scheduled at the Botucatu School of Medicine Hospital das Clínicas. Subjects were considered to have refused the medical evaluation if three unsuccessful attempts were made.

During the medical evaluation, the diagnosis was confirmed and the hyperhidrosis was classified (as $\mathrm{PH}$ or $\mathrm{SH}$ ). The disorder and its treatment options were explained and, if interested, the patient was invited to schedule a consultation at the thoracic surgery outpatient clinic of the Hospital das Clínicas.

All data collected were stored in a specific database (Epi Info, version 6.04) for later descriptive statistical analysis.

We used Cronbach's alpha to test the reliability of the QoL questionnaire and varimax rotation to evaluate the importance of each domain in the final QoL questionnaire score. Principal component analysis for eigenvalues equal to or higher than 0.5 was used in order to extract the factors.

\section{RESULTS}

The interviewers visited 1,351 households comprising a total of 4,113 residents, of whom 2,150 (52.3\%) were females and 1,963 (47.7\%) were males. Ages ranged from 5 to 97 years, with a mean of $38.3 \pm$ 21.2 years. Regarding age and gender distribution (Figure 1), the sample was very similar to the general population of the city.

Of the 4,113 residents in the study population, 85 $(2.07 \%)$ reported excessive sweating (Figure 2 ). Of those 85 residents, 51 (60\%) were female. In this subgroup, ages ranged from 5 to 72 years, with a mean of $33.9 \pm 17.3$ years.

The average age at symptom onset was 13.2 \pm 9.9 years, and the areas most often affected were the hands (in 45.9\%) and feet (in 43.5\%). Seventeen subjects (20\%) had already sought the help of a health professional, and 15 had sought out a physician and/or two other professionals. The most common psychosocial effect of excessive sweating was embarrassment $(33.3 \%)$, and the predisposing factor was nervousness (34.1\%).

A medical consultation at home or at the outpatient clinic was offered to all subjects who reported excessive sweating. Of those 85 subjects, $51(60 \%)$ agreed to the medical consultation and $43(40 \%)$ refused or did not attend. After evaluation, the prevalence of $\mathrm{PH}$ was found to be $0.93 \%$, the diagnosis having been confirmed in 23 subjects (45\%), whereas 15 (29.4\%) had been diagnosed with $\mathrm{SH}$ and 13 (25.5\%) were found to have no hyperhidrosis (Figure 3 ). Of the subjects diagnosed with $\mathrm{SH}, 13$ (87\%) were female, and the prevalence was highest in the 50- to 70-year age range; the causes of $\mathrm{SH}$ were menopause, obesity, and thyroid disorders. Of the 13 subjects who believed that they had hyperhidrosis but were diagnosed with normal sweating after medical evaluation, 10 (77\%) were male. 


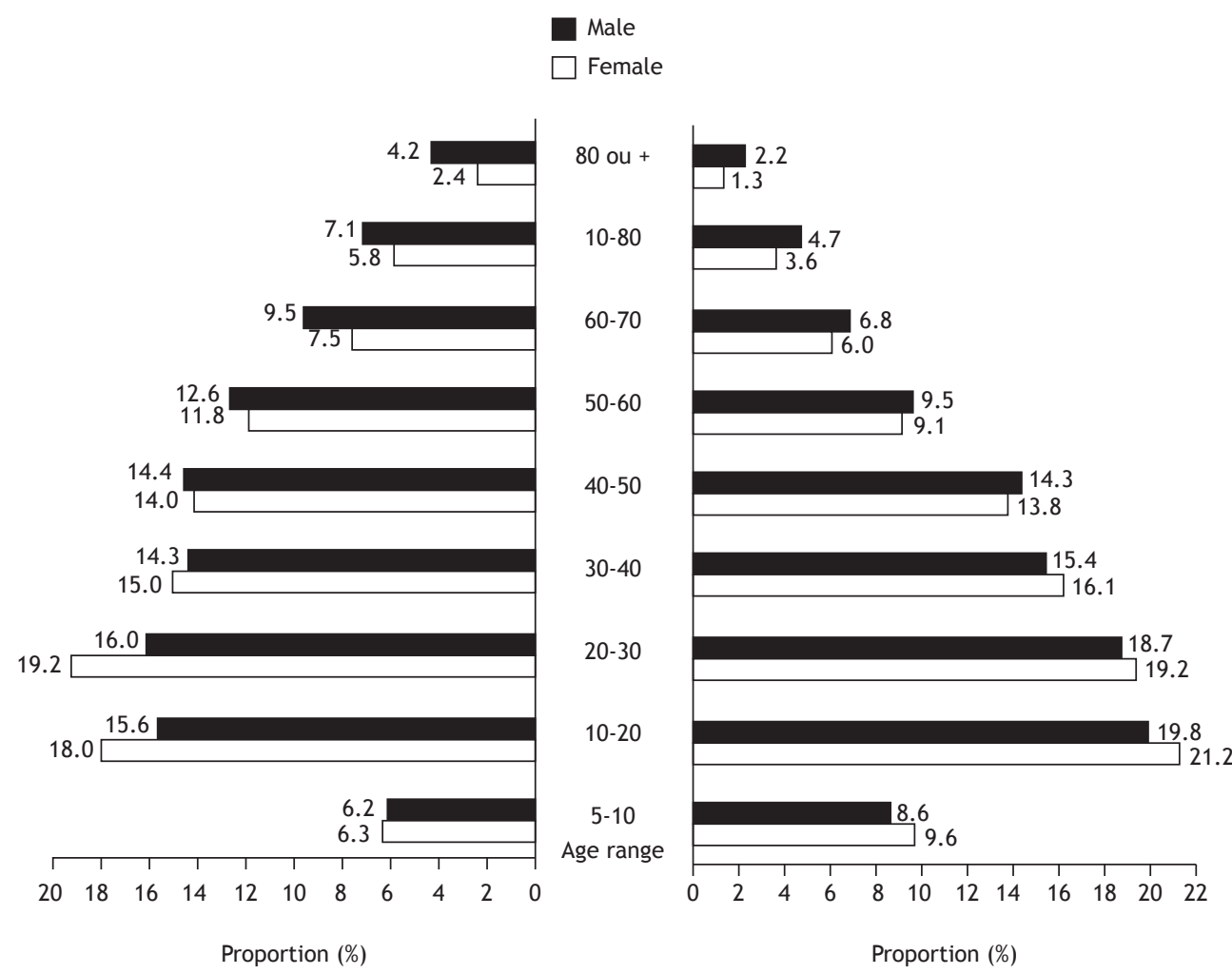

Figure 1. Age and gender distribution of the population over 5 years of age: left side, population of Botucatu ( $\mathrm{N}=$ $113,055)$; right side, population sample studied $(n=4,113)$.

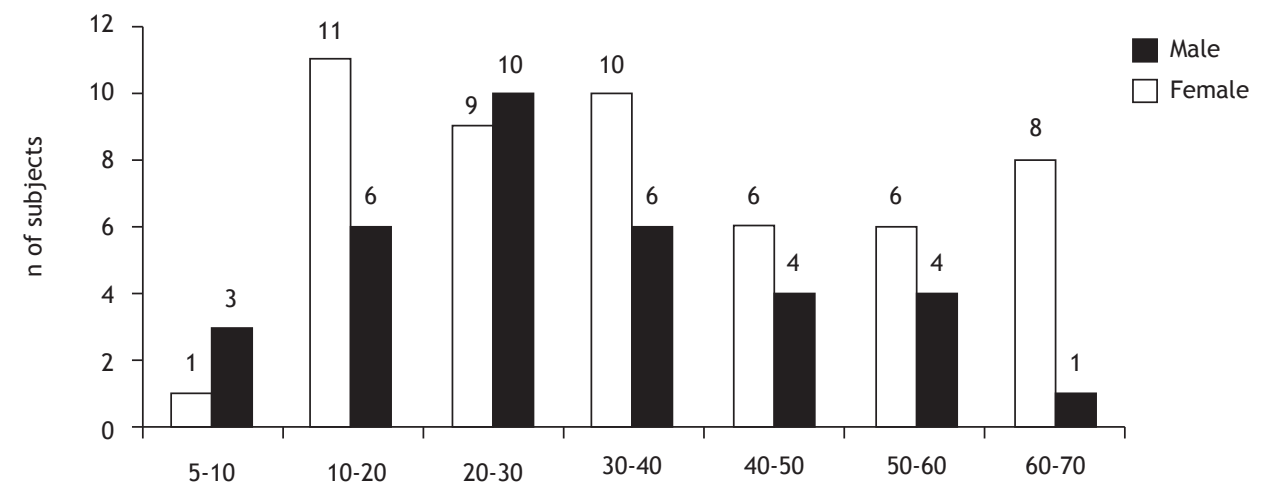

Age range

Figure 2. Number of subjects who reported excessive sweating $(n=85)$, by age range and gender.

Of the subjects diagnosed with $\mathrm{PH}, 83 \%$ were female (Figure 4). The most common occupations were student (in 43\%) and house cleaner (in 21\%). The age at symptom onset was $<5$ years in 4 subjects, $5-10$ years in 7, 10-15 years in 3, 15-20 years in 4 , and $>20$ years in 5 .

In subjects with $\mathrm{PH}$, the most common sites of excessive sweating were the hands (in 73.9\%), feet (in 60.9\%), armpits (in 30.4\%), and scalp/face (in $12.9 \%$ ). The most common psychosocial effect was embarrassment (in $33.3 \%$ ), followed by shame (in $25.0 \%$ ) and discomfort (16.7\%). The most prevalent predisposing factor was nervousness (39.1\%), followed by anxiety $(21.7 \%)$. A family history of hyperhidrosis was reported by 7 subjects (30.0\%). Only 6 subjects (26.1\%) had sought the help of a medical professional.

Of the subjects with $\mathrm{PH}, 48 \%$ reported poor or very poor QoL, the same proportion reported good QoL, and only $4.35 \%$ reported excellent QoL. Of the domains evaluated (functional-social, personal, emotional, and special conditions), the most affected was the special conditions domain, with high scores especially for situations of tension or worry in enclosed environments, followed by the functional-social domain, with high 


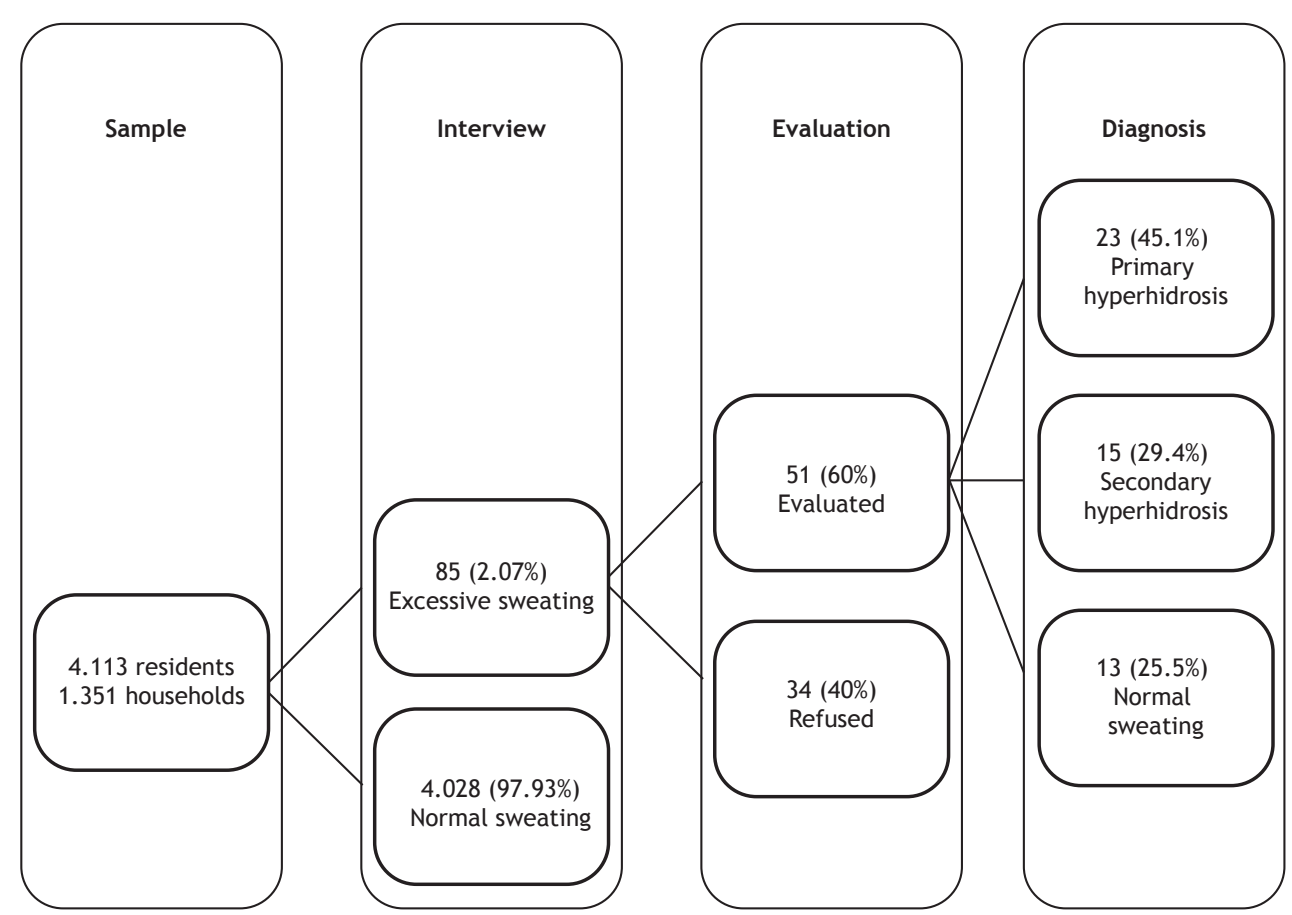

Figure 3. Population interviewed and subjects evaluated by a physician.

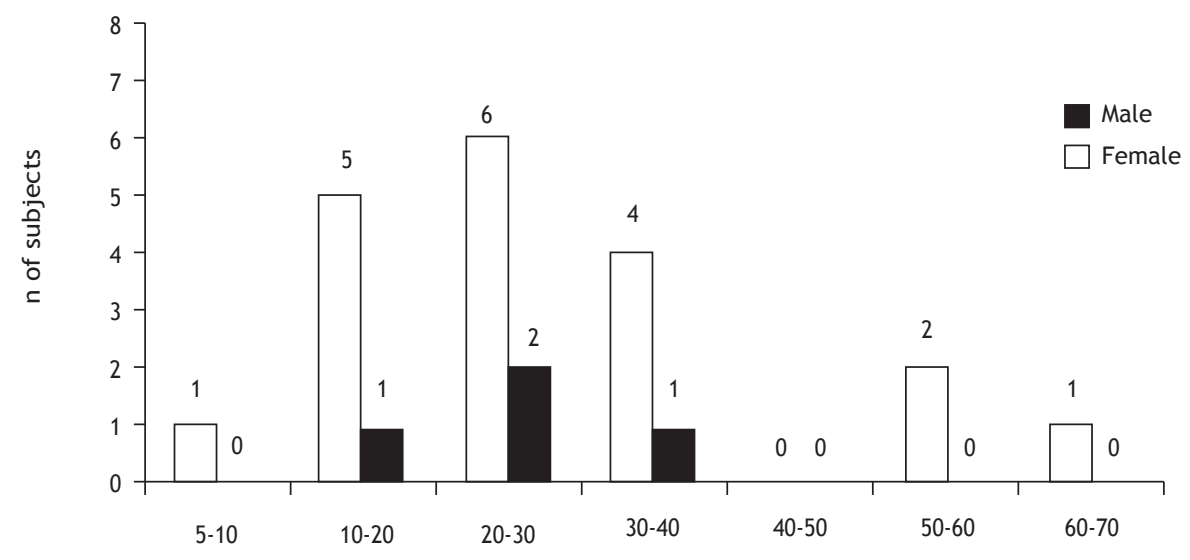

Age range

Figure 4. Number of subjects with primary hyperhidrosis $(n=23)$, by age range and gender.

scores for writing, performing manual tasks, holding objects, and shaking hands. The final mean score for QoL was $52.4 \pm 18.7$, and 7 subjects had a final score $>60$; of those 7 subjects, 4 had a score above 70 and only 2 had a score above 80 .

High reliability was observed for the final score of QoL ( $a=0.9079$ ), the functional-social domain ( $a=$ 0.8624 ), and the personal domain ( $a=0.9033$ ), as evaluated by Cronbach's alpha. The emotional domain $(a=0.5963)$ and the special conditions domain ( $a=$ 0.5883 ) were considered to be of moderate reliability.

\section{DISCUSSION}

Data on the prevalence of hyperhidrosis are quite scarce in the medical literature. We found only 12 studies $^{(7,14-24)}$ that reported statistical data on the prevalence of this disorder; however, the methods used in all those studies raise questions.

The first study on the incidence of hyperhidrosis was performed by Adar et al. (14) The authors reference an epidemiological pilot study involving Israeli youth, among whom the incidence of hyperhidrosis reportedly ranged from $0.6 \%$ to $1.0 \%$. Although that study was 
cited by several authors, there are no data regarding the methods used to arrive at these values.

In our study, the prevalence of hyperhidrosis after the application of a questionnaire by trained interviewers was above $2 \%$, as observed by Strutton et al. ${ }^{(15)}$ However, after medical evaluation, $25 \%$ of the patients that reported excessive sweating actually showed normal sweating and $30 \%$ had $\mathrm{SH}$. Consequently, more than half of the subjects that reported excessive sweating did not actually have $\mathrm{PH}$. Therefore, after medical evaluation, the estimated prevalence of $\mathrm{PH}$ decreased to less than $1 \%$, as in the study by Adar et al. ${ }^{(14)}$ This demonstrates the importance of medical evaluation for the correct estimation of prevalence. In 2013, Augustin et al. ${ }^{(23)}$ published a study that included 14,336 employees of 52 German companies. In that study, all of the subjects were evaluated by dermatologists and the prevalence rate was $16.3 \%$. However, the study sample included cases of $\mathrm{PH}$ and $\mathrm{SH}$, given that $68 \%$ of the patients reported generalized hyperhidrosis and only $28 \%$ reported hyperhidrosis of the hands, armpits, feet, or other areas.

In the study conducted by Strutton et al., (15) the prevalence projected for the general population of the United States was $2.8 \%$. In that study, a previously validated questionnaire ${ }^{(15)}$ was applied to a sample of 150,000 subjects, to determine the prevalence of hyperhidrosis. The authors applied the same method used in our study, although the subjects identified as hyperhidrosis patients by the questionnaire were not evaluated by a physician to confirm the diagnosis. Therefore, that sample could have included some subjects with $\mathrm{SH}$ or subjects that thought they had hyperhidrosis but in fact sweated a normal amount.

Unfortunately, in our study, some subjects refused medical evaluation, and others were not at home at the scheduled time or did not go to the outpatient clinic on the scheduled day. Patient refusal to undergo medical evaluation could be attributable to several factors, such as fear of being diagnosed with a disease, fear of being induced to undergo a surgical procedure, embarrassment or even resignation regarding the condition, or lack of interest because the sweating does not impair daily activities. There was a similar situation in the Strutton et al. study, ${ }^{(15)}$ in which only $64 \%$ of the participants completed the questionnaire required to estimate the prevalence of hyperhidrosis in the general population of the United States.

In a study conducted in Japan, Fujimoto et al.(22) applied questionnaires at companies and in schools. The authors analyzed 5,807 subjects between 5 and 64 years of age and reported a prevalence of $12.76 \%$. Again, the subjects were not examined by a physician and the prevalence might therefore be overestimated.

In a study performed in Taiwan by Chu et al., (19) the authors reported a prevalence of $\mathrm{PH}$ of $0.072 \%$. Data were collected from a database administered by the National Health Insurance Program (of Taiwan), according to code 780.8 of the International
Classification of Diseases, 9th revision. In fact, that prevalence rate referred only to the subjects who sought medical treatment and not to the general population. The difference in comparison with the (higher) prevalence reported in other studies can be explained by the fact that not all subjects with $\mathrm{PH}$ seek medical treatment. In our study, only $0.41 \%$ of subjects in the sample had discussed the problem of excessive sweating with a health professional and, of those, only $0.15 \%$ had $\mathrm{PH}$.

The age and gender distribution of the population included in our study was quite representative of the city of Botucatu; that was not observed in other studies. ${ }^{(7,16-25)}$

Researchers in China published three studies on the prevalence of hyperhidrosis in the country. Tu et al. ${ }^{(17)}$ performed a study in a sample of 13,000 high school and college students between 15 and 22 years of age in the city of Fuzhou. A questionnaire was applied, and the students under suspicion of having $\mathrm{PH}$ were later interviewed by a physician. The method used in order to identify subjects with hyperhidrosis was similar to that used in our study; however, the Tu et al. study ${ }^{(17)}$ included only one age range (adolescents), and the prevalence was found to be $4.59 \%$. Another study conducted in China ${ }^{(16)}$ used the same method and age range as the $\mathrm{Tu}$ et al. study ${ }^{(17)}$, albeit with a larger study population (33,000 students), and reported a prevalence of $4.36 \%$. A third study ${ }^{(24)}$ reported the results of a nationwide survey performed in the seven regions of continental China. A self-report hyperhidrosis questionnaire was sent to 70,000 college students between 18 and 23 years of age. A total of 67,492 completed questionnaires were evaluated, and the prevalence found was $2.08 \%$. Those three studies showed a selection bias, because the samples were not representative of the general population. The prevalence of $\mathrm{PH}$ is known to be higher in the age ranges evaluated (children and adolescents), which might have resulted in its overestimation.

In 2013, Stefaniak et al.(21) evaluated an adult population in Poland, including only students of medicine and odontology, who completed a questionnaire and were later subjected to gravimetry. In their responses on the questionnaire, $16.7 \%$ of the students reported suffering from hyperhidrosis, although, after an objective evaluation, only $8 \%$ were found to have $\mathrm{PH}$. Therefore, the authors concluded that questionnaires may lead to false-positive results, and that an objective evaluation-which in our study was performed by a physician-is necessary.

Three studies on the prevalence of hyperhidrosis were performed in Brazil. $(7,18,20)$ One was performed in a population sample of the city of Blumenau and found a prevalence of $9 \%$. ${ }^{(18)}$ The study included only 500 subjects $\geq 18$ years of age who were randomly approached in the bus terminals of the city. The individuals who were randomly interviewed did not represent a sample statistically large enough to estimate the prevalence of $\mathrm{PH}$ in a city of more 
than 100,000 inhabitants, and there was no medical interview to confirm the diagnosis; therefore, some subjects with normal sweating or SH may have been included. Furthermore, children and adolescents were excluded from that study.

Westphal et al., (20) in a study involving 293 students at the Amazonas School of Medicine, reported a prevalence of $5.5 \%$. A questionnaire was prepared to evaluate the presence of hyperhidrosis, and a researcher interviewed the subjects who presumably had $\mathrm{PH}$, to confirm the diagnosis. The authors did not disclose whether the interviewer was a physician, and students who had already been subjected to video-assisted thoracoscopic sympathectomy for the treatment of $\mathrm{PH}$ were excluded from the study.

Lima et al. ${ }^{(7)}$ evaluated 447 medical students in the Brazilian state of Sergipe. Hyperhidrosis was found in $14.76 \%$ of the students, a high prevalence in comparison with that reported in other studies. The students were interviewed by professors, and only $22.72 \%$ had their diagnosis confirmed by a physician. As in our study, the prevalence rate might be lower, because the medical evaluation showed that many subjects sweated a normal amount.
In our study, the prevalence of $\mathrm{PH}$ was slightly higher among women, and the proportion of women diagnosed with $\mathrm{PH}$ increased significantly after the medical evaluation, because most of the men were shown to sweat a normal amount. ${ }^{(10,27)}$

In our study, more than $50 \%$ of the subjects diagnosed with $\mathrm{PH}$ reported excellent or good QoL, in contrast to the study conducted by de Campos et al., (26) in which $100 \%$ of the subjects reported poor or very poor QoL. That discrepancy can be explained by the fact that we conducted an active search for patients with $\mathrm{PH}$, whereas Campos et al. ${ }^{(26)}$ studied patients who sought medical treatment.

We conclude that the estimated prevalence of $\mathrm{PH}$ is near $1 \%$, small in comparison with the number of subjects who report excessive sweating. The disorder affects the QoL in nearly $50 \%$ of subjects. Additional methodologically appropriate prevalence studies are needed in order to establish the true worldwide prevalence of hyperhidrosis.

\section{ACKNOWLEDGMENTS}

We thank Professor Dr. Luana Carandina for her contribution to our study.

\section{REFERENCES}

1. Cerfolio RJ, De Campos JR, Bryant AS, Connery CP, Miller DL, DeCamp MM, et al. The Society of Thoracic Surgeons expert consensus for the surgical treatment of hyperhidrosis. Ann Thorac Surg. 2011;91(5):1642-8. https://doi.org/10.1016/J. athoracsur.2011.01.105

2. Vazquez LD, Staples NL, Sears SF, Klodell CT. Psychosocial functioning of patients after endoscopic thoracic sympathectomy. Eur J Cardiothorac Surg. 2011;39(6):1018-21. https://doi.org/10.1016/i ejcts.2011.01.059

3. Kaufmann H, Saadia D, Polin C, Haques S, Singleton A, Singleton A Primary hyperhidrosis--evidence for autosomal dominant inheritance. Clin Auton Res. 2003;13(2):96-8. https://doi.org/10.1007/s10286-0030082-x

4. Yamashita N, Tamada $Y$, Kawada M Mizutani K, Watanabe D, Matsumoto $Y$. Analysis of family history of palmoplantar hyperhidrosis in Japan. J Dermatol. 2009:36(12):628-31. https://doi. org/10.1111/j.1346-8138.2009.00732.x

5. Hornberger J, Grimes K, Naumann M, Glaser DA, Lowe NJ, Naver $H$, et al. Recognition, diagnosis, and treatment of primary foca hyperhidrosis. J Am Acad Dermatol. 2004;51(2):274-86. https://doi. org/10.1016/j.jaad.2003.12.029

6. Park EJ, Han KR, Choi H, Kim W, Kim C. An epidemiological study of hyperhidrosis patients visiting the Ajou University Hospita hyperhidrosis center in Korea. J Korean Med Sci. 2010;25(5):772-5. https://doi.org/10.3346/jkms.2010.25.5.772

7. Lima SO, Aragão JF, Machado Neto J, Almeida KB, Menezes LM, Santana VR. Research of primary hyperhidrosis in students of medicine of the State of Sergipe, Brazil. An Bras Dermatol. 2015;90(5):661-5. https://doi.org/10.1590/abd1806-4841.20153859

8. Tabet JC, Bay JW, Magdinec M. Essential hyperhidrosis. Current therapy. Cleve Clin O. 1986;53(1):83-8. https://doi.org/10.3949/ ccjm.53.1.83

9. Leung AK, Chan PY, Choi MC. Hyperhidrosis. Int J Dermatol. 1999;38(8):561-7. https://doi.org/10.1046/j.1365-4362.1999.00609.x

10. Kauffman $P$, Campos JR. Video-assisted thoracic sympathectomy for the treatment of axillary hyperhidrosis. J Bras Pneumol. 2011;37(1):45. https://doi.org/10.1590/S1806-37132011000100002

11. Campos JR, Kauffman P. Video-assisted thoracic sympathectomy in the treatment of primary hyperhidrosis. J Bras Pneumol. 2007:33(3):15-7.
2. Boscardim PC, Oliveira RA, Oliveira AA, Souza JM, Carvalho RG Thoracic sympathectomy at the level of the fourth and fifth ribs for the treatment of axillary hyperhidrosis. J Bras Pneumol. 2011;37(1):6 12. https://doi.org/10.1590/S1806-37132011000100003

13. Montessi J, Almeida EP, Vieira JP, Abreu Mda M, Souza RL, Montessi OV. Video-assisted thoracic sympathectomy in the treatment of primary hyperhidrosis: a retrospective study of 521 cases comparing different levels of ablation. J Bras Pneumol. 2007;33(3):248-54 https://doi.org/10.1590/S1806-37132007000300004

14. Adar R, Kurchin A, Zweig A, Mozes M. Palmar hyperhidrosis and its surgical treatment: a report of 100 cases. Ann Surg. 1977;186(1):34 41. https://doi.org/10.1097/00000658-197707000-00006

15. Strutton DR, Kowalski JW, Glaser DA, Stang PE. US prevalence of hyperhidrosis and impact on individuals with axillary hyperhidrosis: results from a national survey. J Am Acad Dermatol. 2004;51(2):241 8. https://doi.org/10.1016/j.jaad.2003.12.040

16. Li X, Chen R, Tu YR, Lin M, Lai FC, Li YP, et al. Epidemiological survey of primary palmar hyperhidrosis in adolescents. Chin Med $J$ (Engl). 2007;120(24):2215-7

17. Tu YR, Li X, Lin M, Lai FC, Li YP, Chen JF, et al. Epidemiologica survey of primary hyperhidrosis in adolescent in Fuzhou of People's Republic of China. Eur J Cardiothorac Surg. 2007;31(4):737-9. https:// doi.org/10.1016/j.ejcts.2007.01.020

18. Felini R, Demarchi AR, Fistarol ED, Matiello M, Delorenze LM. Prevalence of hyperhidrosis in the adult population of Blumenau-SC Brazil. An Bras Dermatol. 2009;84(4):361-6. https://doi.org/10.1590/ S0365-05962009000400007

19. Chu D, Chen RC, Lee $C H$, Yang NP, Chou P. Incidence and frequency of endoscopic sympathectomy for the treatment of hyperhidrosis palmaris in Taiwan. Kaohsiung J Med Sci. 2010;26(3):123-9. https:// doi.org/10.1016/S1607-551X(10)70018-8

20. Westphal FL, de Carvalho MA, Lima LC, de Carvalho BC, Padilla $R$ Araújo KK. Prevalence of hyperhidrosis among medical students. Rev Col Bras Cir. 2011;38(6):392-7. https://doi.org/10.1590/S010069912011000600005

21. Stefaniak T, Tomaszewski KA, Proczko-Markuszewska M, Idesta A, Royton A, Abi-Khalil C. Is subjective hyperhidrosis assessment sufficient enough? Prevalence of hyperhidrosis among young Polish adults. J Dermatol. 2013:40(10):819-23. https://doi.org/10.1111/13468138.12238 
22. Fujimoto T, Kawahara K, Yokozeki H. Epidemiological study and considerations of primary focal hyperhidrosis in Japan: from questionnaire analysis. J Dermatol. 2013;40(11):886-90. https://doi. org/10.1111/1346-8138.12258

23. Augustin $M$, Radtke MA, Herberger $K$, Kornek $T$, Heigel $H$ Schaefer I. Prevalence and disease burden of hyperhidrosis in the adult population. Dermatology. 2013;227(1):10-3. https://doi. org/10.1159/000351292

24. Lai FC, Tu YR, Li YP, Li X, Lin M, Chen JF, et al. Nation wide epidemiological survey of primary palmar hyperhidrosis in the People's Republic of China. Clin Auton Res. 2015;25(2):105-8. https://doi.org/10.1007/s10286-014-0259-5

25. Brasil. Ministério do Planejamento, Orçamento e Gestão. Instituto Brasileiro de Geografia e Estatística (IBGE). Censo 2007. Contagem populacional. Rio de Janeiro: IBGE; 2007.

26. de Campos JR, Kauffman P, Werebe Ede C, Andrade Filho LO Kusniek S, Wolosker N, et al. Quality of life, before and after thoracic sympathectomy: report on 378 operated patients. Ann Thorac Surg 2003;76(3):886-91. https://doi.org/10.1016/S0003-4975(03)00895-6

27. Kauffman $P$, Cinelli M Jr, Wolosker $M$, Leão LE. Treatment of palmar hyperhidrosis by cervico-thoracic sympathectomy [Article in Portuguese]. AMB Rev Assoc Med Bras. 1978;24(1):29-30. 